\title{
Erratum to: Adsorption of Heavy Metal Ions onto Surface-Functionalised Polymer Beads. I. Modelling of Equilibrium Isotherms by Using Non-Linear and Linear Regression Analysis
}

\author{
Gabriela-Nicoleta Moroi • Ecaterina Avram • \\ Laura Bulgariu \\ Published online: 14 October 2016 \\ (C) Springer International Publishing Switzerland 2016

\section{Erratum to: Water Air Soil Pollut \\ DOI 10.1007/s11270-016-2953-5}

The original article published online on 12 July had an error. Figure 1b lacks the unit ' $\mathrm{nm}$ ' in the middle right of the image. The corrected figure is shown in the next page; the original publication was also updated to reflect the changes.

The online version of the original article can be found at http://dx. doi.org/10.1007/s11270-016-2953-5.

\section{G.-N. Moroi $(\bowtie)$}

Laboratory of Polyaddition and Photochemistry, Institute of Macromolecular Chemistry "Petru Poni", Romanian Academy, Iași 700487, Romania

e-mail: gmoroi@icmpp.ro

E. Avram

Laboratory of Functional Polymers, Institute of Macromolecular Chemistry "Petru Poni", Romanian Academy, Iași 700487 ,

Romania

L. Bulgariu

Faculty of Chemical Engineering and Environmental Protection, Technical University “Gh. Asachi”, Iaşi 700050, Romania 


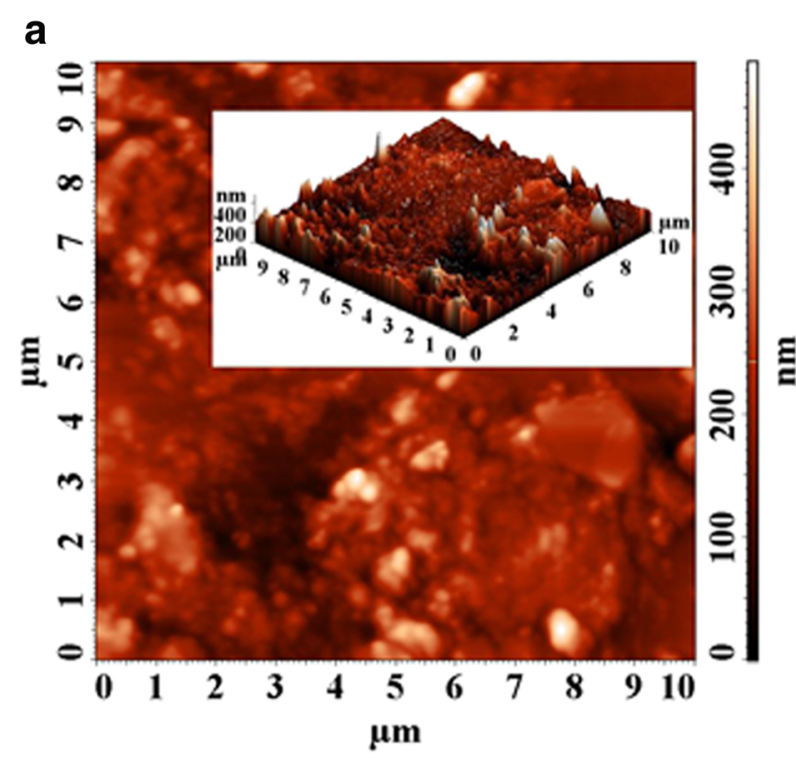

b

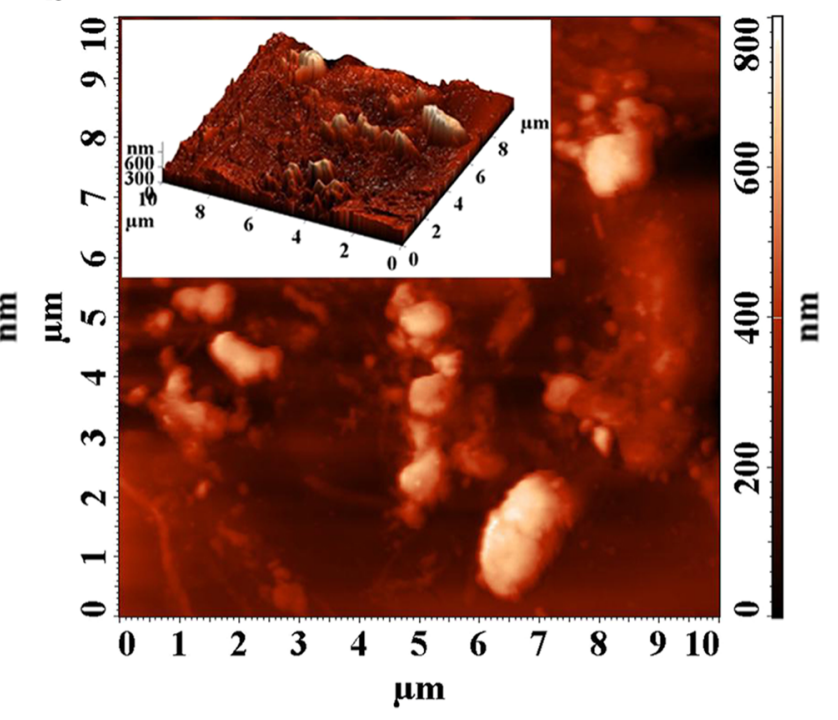

